\title{
Incremental value of live/real-time three-dimensional transesophageal echocardiography over the two-dimensional technique in the identification of accessory liver lobe presenting as a right atrial mass
}

\author{
Nishank Nooli ${ }^{1}$, Panos $\operatorname{Vardas}^{1}$, Yashaswi Koguru ${ }^{2}$, and Navin C. Nanda ${ }^{3}$ \\ ${ }^{1}$ The University of Alabama at Birmingham School of Medicine \\ ${ }^{2}$ The University of Alabama at Birmingham \\ ${ }^{3}$ Affiliation not available
}

March 22, 2021

\begin{abstract}
We describe an adult patient with a large right atrial mass which was found to have the same echotexture as adjacent liver tissue on two-dimensional transesophageal echocardiography (2DTEE). By using live/real-time three-dimensional transesophageal echocardiography (3DTEE), we were able to examine the mass by meticulous cropping and confirm the echotexture was similar to liver tissue throughout its extent. Three-dimensional cropping also redemonstrated in a definitive manner that the mass was in continuity with liver. Thus, in our patient 3DTEE served to increase the confidence level of making a definitive diagnosis of a supernumerary lobe of liver. To the best of our knowledge, the incremental value of 3DTEE over 2DTEE in diagnosing a supernumerary liver lobe has not been reported previously. The mass was surgically resected and the findings confirmed as liver tissue by pathological examination.
\end{abstract}

Title Page

Title: Incremental value of live/real time three-dimensional transesophageal echocardiography over the twodimensional technique in the identification of accessory liver lobe presenting as a right atrial mass

Running head: Echocardiography of supernumerary liver lobe

Authors:

Nishank Patel Nooli, MD

Assistant Professor

Division of Cardiothoracic Anesthesia,

Department of Anesthesiology and Perioperative Medicine

University of Alabama at Birmingham

Panayotis Vardas, MD

Division of Cardiothoracic Surgery

Department of Surgery

University of Alabama at Birmingham 
Yashaswi Koguru, MBBS

Department of Medicine

University of Alabama at Birmingham

Navin C. Nanda, MD

Division of Cardiovascular disease

Department of Medicine

University of Alabama at Birmingham

Corresponding Author:

Nishank Patel Nooli, MD

Assistant Professor

Division of Cardiothoracic Anesthesia,

Department of Anesthesiology and Perioperative Medicine

University of Alabama at Birmingham

$61919^{\text {th }}$ Street South, Suite 5210B

Birmingham, Alabama - 35249-6810

USA

Email:nnooli@uabmc.edu

Fax: None

\section{Hosted file}

Nooli Accessory liver lobe as RA mass.pdf available at https://authorea.com/users/403069/ articles/514731-incremental-value-of-live-real-time-three-dimensional-transesophagealechocardiography-over-the-two-dimensional-technique-in-the-identification-of-accessoryliver-lobe-presenting-as-a-right-atrial-mass

\section{Hosted file}

Figure legend.pdf available at https://authorea.com/users/403069/articles/514731-incrementalvalue-of-live-real-time-three-dimensional-transesophageal-echocardiography-over-the-twodimensional-technique-in-the-identification-of-accessory-liver-lobe-presenting-as-aright-atrial-mass 

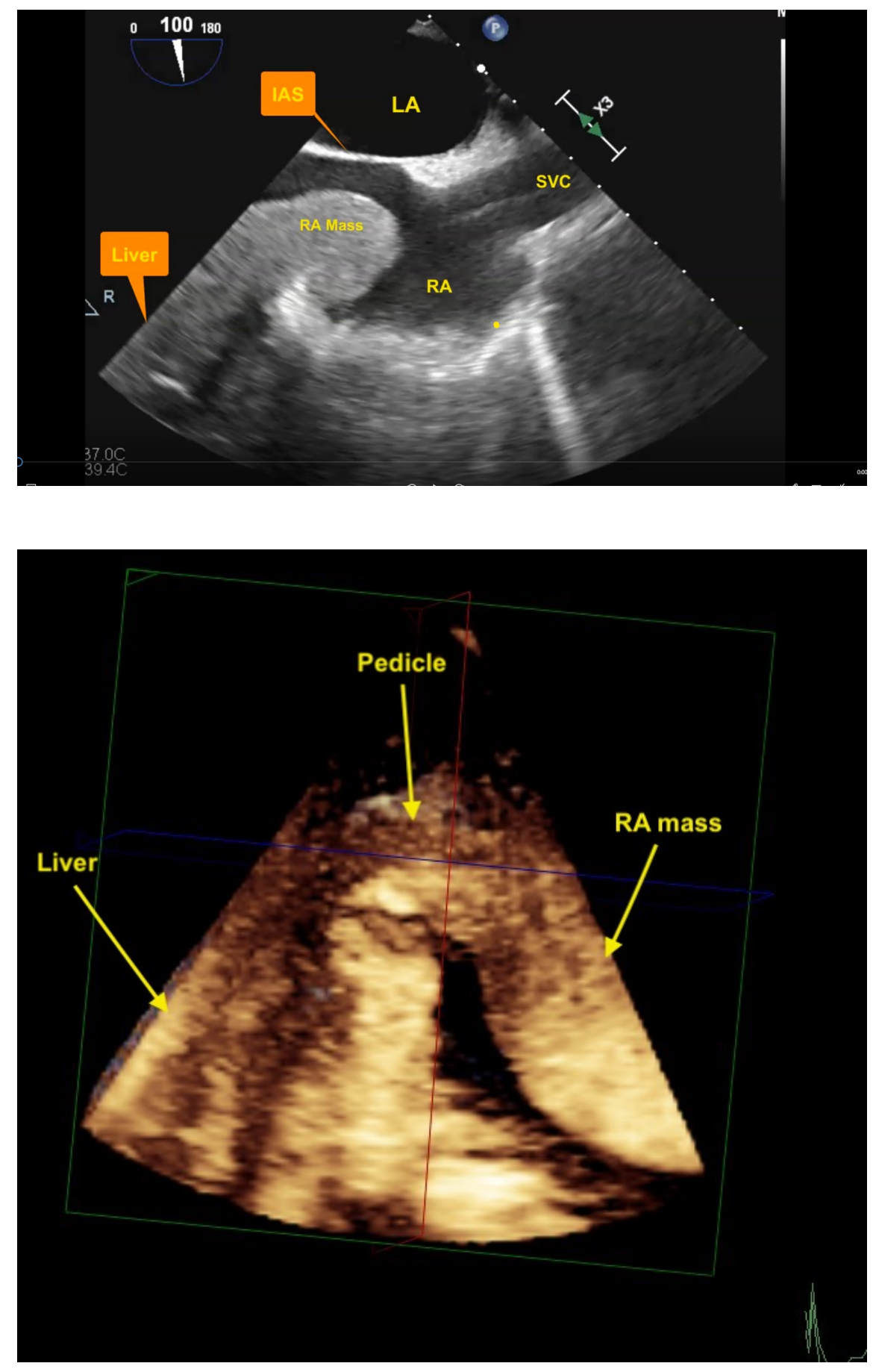


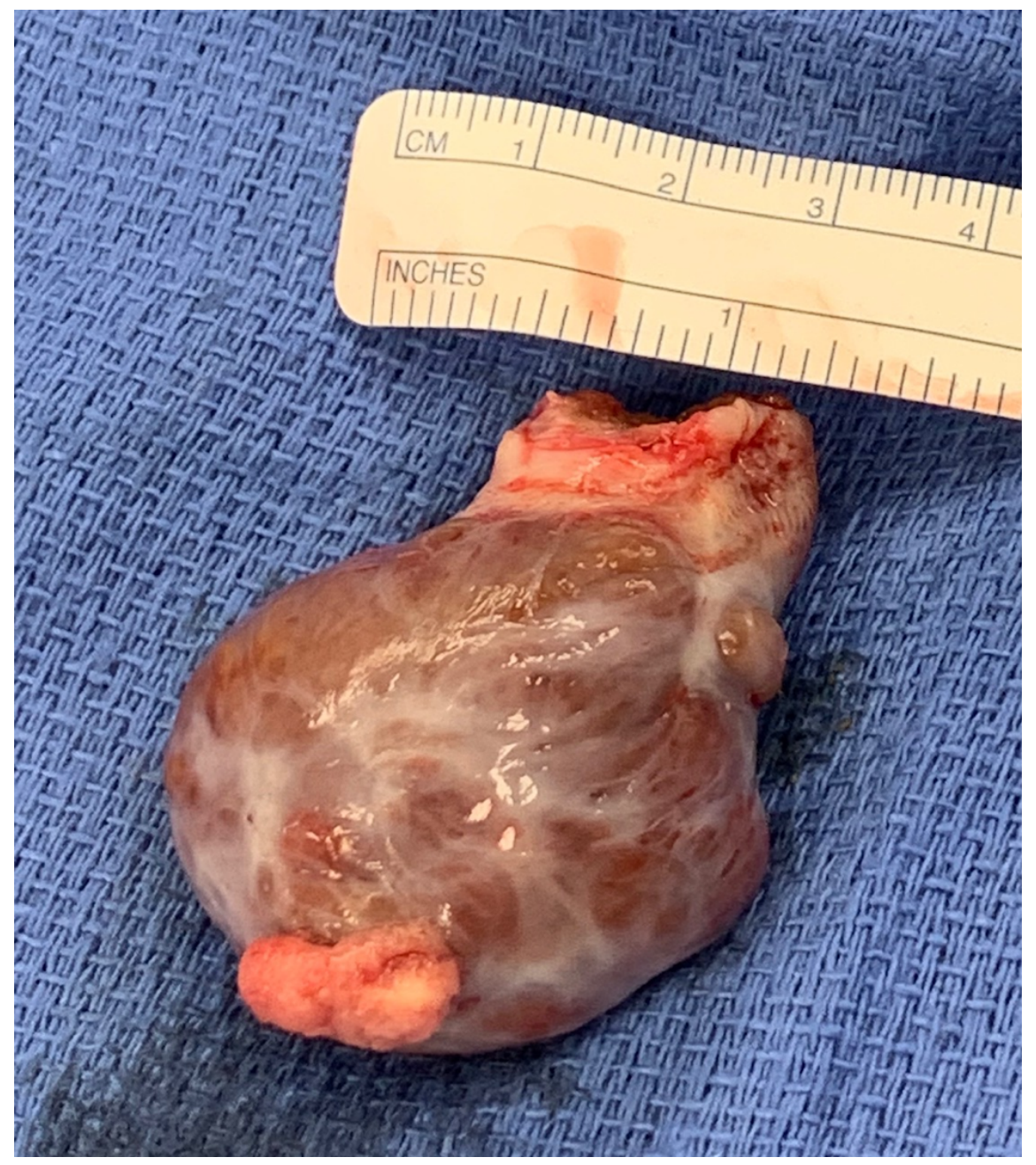

